\title{
PENGEMBANGAN MODEL QUALITY IMPROVEMENT PROGRAM (QIP) UNTUK MENINGKATKAN KINERJA DOSEN PADA PERGURUAN TINGGI SWASTA
}

\section{DEVELOPMENT OF MODEL QUALITY IMPROVEMENT PROGRAM (QIP) TO IMPROVE LECTURER PERFORMANCE AT PRIVATE UNIVERSITIES}

\author{
Wati Irnawati
}

Universitas Suryakancana, Jl. Pasirgede Raya, Bojongherang, Cianjur 43216

watiirnawati@yahoo.com

\begin{tabular}{|l|l|l|}
\hline Masuk: 31 Mei 2021 & Penerimaan: 1 Juni 2021 & Publikasi: 28 Juni 2021 \\
\hline
\end{tabular}

\begin{abstract}
ABSTRAK (Garamond 11, buruf besar, cetak tebal)
Penelitian ini bertujuan untuk mendeskripsikan kondisi kualitas dan kuantitas kinerja dosen dalam menjalankan tridharma perguruan tinggi, menganalisis program kinerja dosen yang telah dilakukan untuk mengetahui dampak dari program pengembangan tersebut dan merancang program pengembangan untuk meningkatkan kinerja dosen. Pendekatan yang digunakan dalam penelitian ini adalah pendekatan penelitian dan pengembangan atau Research and Development yang dikemukakan oleh Borg and Gall. Model pengembangan dalam penelitian ini melalui tahap model konseptual, model teoritik, model hipotetik dan model final. Namun pada artikel ini hanya akan membahas sampai pada model teoritik. Temuan-temuan pada penelitian ini adalah masih rendahnya jumlah guru besar, masih banyak perguruan tinggi swasta yang di bawah standar pendidikan tinggi, kompetensi dosen masih belum optimal dalam menjalankan tridharma perguruan tinggi terutama dalam bidang penelitian dalam hal ini masih rendahnya kapasitas dosen dalam publikasi ilmiah, masih ada dosen yang belum memiliki jabatan fungsional serta tuntutan stakeholder yang semakin kuat agar perguruan tinggi swasta melakukan perubahan-perubahan dalam rangka meningkatkan kualitas tata kelola perguruan tinggi sehingga menghasilkan lulusan yang berkualitas. Hasil pada penelitian ini berupa Program Pengembangan Kinerga Dosen Terpadu diharapkan mampu meningkatkan kinerja dosen dalam menjalankan tridharma perguruan tinggi. Terutama dalam publikasi ilmiah, yang pada akhirnya akan berdampak pada peningkatan produktivitas dosen sehingga dapat berkontribusi pada pengembangan perguruan tinggi swasta menuju good university governance.
\end{abstract}

Kata Kunci : Program Pengembangan Kinerja, Dosen Terpadu

This study aims to describe the quality and quantity of performance of lecturers in running tridharma universities, analyze the performance programs of lecturers that have been conducted to know the impact of the development program and design development programs to improve the performance of lecturers. The approach used in this research is the research and development approach or Research and Development put forward by Borg and Gall. The development model in this study went through conceptual model stages, theoretical models, bypothetical models and final models. But this article will only discuss the theoretical model. The findings in this study are still low number of professors, there are still many private universities that are below the standard of bigher education, the competence of lecturers is still not optimal in running the tridharma of universities, especially in the field of research in this case the low capacity of lecturers in scientific publications, there are still lecturers who do not have functional positions and the demands of stakeholders are getting stronger so that private universities make changes and lam order to improve the quality of college governance so as to produce

qualified graduates. The results of this study in the form of Integrated Lecturer Kinerga Development Program is expected to improve the performance of lecturers in running the tridharma of universities. Especially in 
scientific publications, which will ultimately have an impact on improving the productivity of lecturers so as to contribute to the development of private universities towards good university governance.

Keyword: Performance Development Program, Integrated Lecturer

\section{PENDAHULUAN}

Perguruan tinggi swasta merupakan institusi pendidikan tinggi milik masyarakat yang menyelenggarakan pendidikan tinggi berdasarkan mandat akademik yang diberikan pemerintah dan pendelegasian wewenang pengelolaan sumber daya dari yayasan. Dengan demikian melaksanakan pendidikan yang bermutu dan manajemen yang professional, terbuka dan demokratis. Prinsip profesional, terbuka dan demokratis adalah bagian sistem administrasi dan manajemen pendidikan yang bertujuan untuk meningkatkan kualitas layanan pendidikan yang berorientasi pada mutu. Hal tersebut sesuai dengan prinsip pokok administrasi pendidikan, yaitu memfasilitasi investasi sumber daya manusia melalui layanan pembelajaran yang bermutu (Satori, 2016).

Berdasarkan data dari Kementerian Riset, Teknologi, dan Pendidikan Tinggi (Kemenristek dikti), hanya terdapat 5.300 orang yang telah meraih gelar sebagai guru besar. Jumlah itu masih kurang dari cukup untuk program studi perguruan tinggi yang jumlahnya mencapai 22 ribu. Sementara itu, jumlah mahasiswa yang belajar di Indonesia mencapai 6,3 juta. Dalam hal ini, seorang profesor harus melayani lebih dari seribu mahasiswa di Indonesia. Data-data ini selanjutnya menjadi catatan penting bagi tim asesor Badan Akreditasi Nasional Perguruan Tinggi (BAN-PT). Di samping itu, pembenahan tenaga kerja pendidikan juga bisa dilihat dari manajemen Pejabat Pengelola Informasi dan Dokumentasi (PPID) di perguruan tinggi. Perbaikan sistem informasi oleh PPID juga perlu dilakukan supaya informasi bisa diberikan lebih terbuka dan lengkap. Perbaikan sistem manajemen ini bisa dilakukan hingga menempatkan secara hati-hati wakil di unit fakultas dan jurusan.

Perguruan tinggi swasta di Indonesia kini sedang menghadapi risiko yang jauh lebih besar dibandingkan dengan sebelumnya, yaitu karena mereka kini harus melindungi reputasinya agar memiliki kemampuan untuk tetap kompetitif. Dilain pihak, tuntutan dan harapan stakeholder yang begitu kuat menuntut agar PTS melakukan perubahan-perubahan dalam pengelolaan akademik yang dianggapnya sudah usang, termasuk meninjau kembali proses perencanaan stratejik dan operasionalnya. Semua factor-faktor dinamis tersebut melatarbelakangi mengapa kemudian diperlukan semacam fresh approach dalam mengelola sebuah PT, yaitu dengan mengintegrasikan manajemen risiko pada semua aktivitas dan proses pegambilan keputusan. Pemimpin PTS yang tidak memiliki "sense of urgency" terhadap perubahan maka organisasi yang dipimpinannya tidak akan mampu beradaptasi dengan lingkungan dan pada akhirnya akan mengalami kegagalan dalam mengelola organisasinya, hal ini senada dengan apa yang di ungkapan oleh Kotter \& Heskett (1997), bahwa Jika "sense of urgency" diabaikan dalam perubahan maka perubahan akan gagal, seperti terlalu cepat puas dengan apa yang telah dikerjakan.

Salah satu komponen penting pada suatu perguruan tinggi adalah dosen. Sehingga kualitas dan mutu dosen dalam menjalankan tugasnya penting untuk dijaga dan terus ditingkatkan. Sebagaimana yang dinyatakan oleh Ramli dan Jalinus (2013), bahwa keberadaan pendidik yang berkualitas merupakan syarat mutlak hadirnya sistem dan praktik pendidikan yang bermutu.

Pengembangan organisasi adalah proses dimana sebuah organisasi mengembangkan kapasital internalnya untuk menjadi lebih efektif sebagai perwujudan nilai kerja yang sesuai dengan misi organisasi agar mampu bertahan dan terus mengalami kemajuan dalam waktu yang lama (Phibin dan Mikush, 1999). 
Pengembangan sebuah organisasi merupakan kebutuhan dan menjadi tantangan tersendiri, khususnya di era yang serba kompetitif. Mewujudkan semangat berkompetisi tersebut, melalui inovasi pengembangan organisasi dibutuhkan pengetahuan dan konsep yang strategis yang efektif untuk melakukan pengembangan sebagai bagian dari esensi perubahan. Peningkatan dan penguatan strategi, struktur dan proses yang mengarahkan pada efektifitas organisasi. Sementara itu, berdasarkan hasil survey awal di Universitas Putra Indonesia (UNPI) Cianjur. Sebagai universitas swasta, UNPI masih harus mengejar standar dan memperbaiki manajemen universitas terutama dalam hal tenaga pendidik, di UNPI Cianjur masih belum memiliki Guru Besar, dan masih sangat sedikit yang sudah memiliki jabatan fungsional dosen. Dari 62 dosen baru 15 orang yang sudah memiliki jabatan fungsional dosen itupun baru asisten ahli dan lektor.

Setelah di analisa, masalah tersebut disebabkan karena para dosen di Universitas Putra Indonesia masih belum optimal menjalankan tridharma perguruan tinggi terutama dalam bidang penelitian. Dari Sejumlah dosen yang ada di UNPI, baru sebagian kecil saja yang produktif dalam riset dan publikasi ilmiah.

Selain itu, meningkatkan universitas berbasis riset juga masih menjadi kesulitan bagi perguruan tinggi yang masih dianggap kecil. Mereka masih berusaha memenuhi tuntutan fakultas, jurusan, dan program studi. Hal tersebut membuat manajemennya tidak efisien dan mubazir, juga membuat perguruan tinggi tidak siap untuk memiliki basis riset. Oleh karena itu, mereka membutuhkan perhatian lebih, misalnya dari Kopertis atau Kemenristek dikti. Sementara itu, perguruan tinggi yang besar, terutama yang berbadan hukum sudah lebih siap untuk diarahkan menjadi universitas riset. Mereka bisa diarahkan untuk menggandeng industri besar dan menjalin kerjasama.

Hal tersebut di atas diperkuat oleh hasil penelitian yang dilakukan oleh Peleyeju dan Ojebiyi (2013) menyatakan bahwa pengelolaan perguruan tinggi harus menjamin penilaian kinerja dosen dilakukan secara menyeluruh dan berkelanjutan dalam upayan meningkatkan kualitas dosen dan kualitas manajemen secara keseluruhan di perguruan tinggi. Sementara itu, menurut Bai et.al. (2014) bahwa evaluasi kinerja dosen merupakan tantangan serius bagi pengelola perguruan tinggi. Selain itu, Langen (2011) juga menyatakan bahwa evaluasi kinerja dosen bertujuan untuk mengembangkan pemahaman tentang praktik evaluasi sehingga para pengelola pendidikan tinggi bisa memastikan bahwa proses pembelajaran yang dilaksanakan dapat berjalan dengan baik.

Beberapa alasan di atas penulis terdorong untuk melakukan riset mengenai Model Pengembangan Universitas dengan fokus pada peningkatan kinerja dosen perguruan tinggi swasta terutama dibidang riset dan publikasi ilmiah.

\section{METODE PENELITIAN}

Pendekatan yang digunakan dalam penelitian ini adalah pendekatan penelitian dan pengembangan atau Research and Development (R\&D) (Borg \& Gall, 2010) [8] dan dilanjutkan eksperimen". Model pengembangan dalam penelitian ini meliputi kegiatan penelitian pendahuluan (preliminary investigation), menentukan rencana dan arah pengembangan (define), pembuatan desain pengembangan (design), melakukan peragaan (demonstrate), pelaksanaan uji coba desain, evaluasi dan revisi (test,evaluation and revision), melakukan pengembangan (development), dan penyajian hasil pengembangan (delivery). 


\section{Pengembangan Model Quality Improvement Program (QIP) untuk Meningkatkan Kinerja Dosen pada Perguruan Tinggi Swasta \\ Wati Irnawati}

Prosedur pengembangan secara sederhana ditunjukkan dalam Gambar berikut ini.

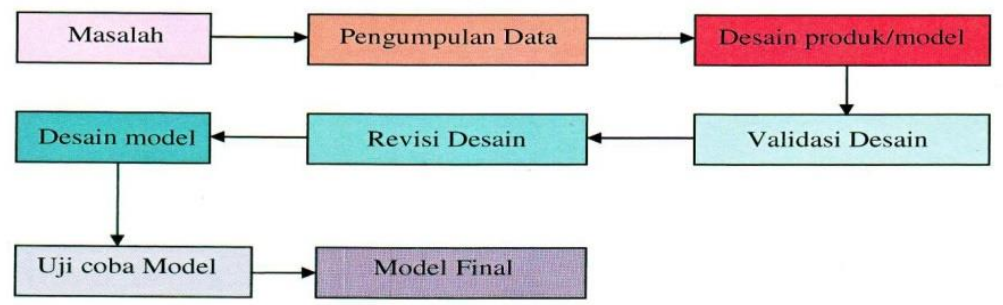

Gambar : Prosedur pengembangan Model

Penelitian ini dilakukan di universitas yang ada di Kabupaten Cianjur yaitu Universitas Putra Indonesia (UNPI) yang beralamat di Jl. Dr. Muwardi No. 66 By Pass Cianjur. Yang menjadi subyek penelitian ini adalah dosen tetap Universitas Putra Indonesia.

Dalam penelitian kualitatif seorang peneliti proses pengumpulan data dapat dilakukan dengan bantuan beberapa instrumen pengumpulan data diantaranya berupa pedoman wawancara, pedoman observasi, dan studi dokumentasi. Tahapan dalam penelitian dan pengembangan ini meliputi kegiatan penelitian pendahuluan (preliminary investigation), menentukan arah dan pembuatan desain pengembangan (design). Setelah itu melakukan peragaan (demonstration), melaksanakan uji coba desain, evaluasi dan revisi (test, evaluationand revision), melakukan pengembangan (development), dan menyajikan hasil pengembangan. Analisis data dilakukan dengan tahapan-tahapan sebagai berikut, (Miles, Huberman, \& Saldana, 2014): (1) data collection, pengumpulan data yang dilakukan dengan cara wawancara, observasi, dan studi dokumentasi; (2) data reduction, mencatat kembali dalam bentuk laporan yang terperinci sambil mengoreksi kembali kelengkapan data tersebut. (3) data display, usaha melihat gambaran keseluruhan atau bagian tertentu dari data penelitian. Biasanya dibuat dalam bentuk Grafik, matrik, dan lain-lain. (3) data conclution, konklusi data atau verifikasi yaitu usaha mencari pengertian dari data yang telah dikumpulkan untuk kegunaan analisis lebih lanjut.

\section{HASIL DAN PEMBAHASAN}

1. Hasil Pengembangan Model

Penelitian dan pengembangan ini bertujuan untuk menghasilkan model atau desain program pengembangan kinerja agar dosen dapat menjalankan tridharma yang dapat dilakukan secara terintegrasi dan simultan. Selain itu, dengan penerapan model ini, dosen dapat meningkatkan kemampuan dossen dalam teknologi informasi dan komitmen profesional di lingkungan UNPI.

Desain program yang dikembangkan, dinyatakan layak digunakan berdasarkan validasi oleh ahli materi, validasi ahli kurikulum, dan hasil ujicoba oleh dosen dan pimpinan serta tanggapan dosen. Penelitian pengembangan ini mengacu pada model pengembangan dan Borg \& Gall, yang dibatasi pada beberapa tahap saja. Tahap-tahap tersebut meliputi: a) tahap pengumpulan informasi; b) tahap perencanaan; c) tahap pengembangan produk; dan d) tahap validasi dan ujicoba. Berdasarkan tahapan tersebut diperoleh:

\section{a. Tahap pengumpulan informasi}

Pada tahap ini dilakukan pengumpulan informasi mengenai penyelenggaraan program peningkatan kualitas yang sasarannya peningkatan kualitas dosen universitas swasta di kabupaten Cianjur. Dilakukan kajian literatur, kurikulum/kompetensi, hasil penelitian, praktik baik di berbagai tempat untuk memotret penyelenggaraan tri dharma perguruan tinggi. Pengumpulan data dilakukan melalui observasi langsung pada universitas swasta yang ada 
dikabupaten Cianjur yaitu UNPI. Dikaji praktik model pada PTS tersebut. Pengumpulan data dalam rangka mendapatkan data empirik tentang pelaksanaan tri dharma perguruan. Data dipergunakan untuk menyusun desain model penyelenggaraan yang dikembangkan. Data empirik dikumpulkan dari dosen PTS di Cianjur.

Berdasarkan hasil survey awal di Universitas Putra Indonesia (UNPI) Cianjur. Sebagai universitas swasta, UNPI masih harus mengejar standar dan memperbaiki manajemen universitas terutama dalam hal tenaga pendidik, di UNPI Cianjur masih belum memiliki Guru Besar, dan masih sangat sedikit yang sudah memiliki jabatan fungsional dosen. Dari 62 dosen hanya 15 orang yang sudah memiliki jabatan fungsional dosen itupun baru asisten ahli dan lektor. Masalah tersebut disebabkan karena para dosen di Universitas Putra Indonesia masih belum optimal menjalankan tridharma perguruan tinggi terutama dalam bidang penelitian. Dari Sejumlah dosen yang ada di UNPI, baru sebagian kecil saja yang produktif dalam riset dan publikasi ilmiah.

\section{b. Tahap perencanaan}

Tahap kedua ini terdiri dari pembuatan model pengembangan kinerja dosn. Instrumen penelitian yang akan digunakan adalah lembar validasi, lembar observasi dan pedoman wawancara. Lembar validasi digunakan untuk mengetahui kelayakan model kinerja dosen yang dapat meningkatkan pelaksanaan Tridharma dosen dan meningkatkan kemampuan dossen dalam teknologi informasi dan komitmen profesional di lingkungan UNPI. Berdasarkan penilaian ahli bahasa dan ahli kurikulum. Ahli materi memberikan penilaian berdasarkan aspek bahasa, materi, dan kesesuaian indikator sedangkan ahli kurikulum memberikan penilaian berdasarkan aspek pemrograman dan tampilan. Lembar observasi dan pedoman wawancara digunakan untuk mengetahui respon dan tanggapan dosen mengenai penggunaan model pengembangan kinerja mencakup pendidikan, penelitian dan pengabdian. Validasi instrumen dilakukan oleh dosen yang ahli pada bidang kurikulum dan manajemen administrasi.

\section{c. Desain Produk}

Pada tahap ini dilakukan pembuatan produk model atau desain pengembangan kinerja dosen. produk pengembangan kinerja diantaranya (1) kualitas dan kuantitas kinerja dosen; (2) Rancangan program kinerja dosen.3.Implementasi program; (3) Rancangan model pengembangan kinerja dosen.

\section{d. Tahap Validasi dan Ujicoba}

Validasi desain merupakan proses penetapan model yang dikembangkan, apakah model yang dikembangkan sudah sesuai. Apabila model yang dikembangkan terdapat kekurangan dan belum mencapai desain yang ideal dan dapat diterapkan model perlu dilakukan revisi.berikut ini hasil ujicoba yang diabil dari wawancara dan observasi.

Dalam uji coba model juga dilakukan observasi tentang out put model terhadap perubahan perilaku dosen. Dari output model akan dilakukan analisis tentang kecenderungan perubahan perilaku dosen. Bila model yang dikembangkan tersebut telah dinyatakan efektif dalam pengujian di lapangan, model tersebut merupakan model final. Selanjutnya dapat dilakukan langkah berikutnya yaitu diseminasi terhadap model atau penyebaran model secara massa

Observasi dilakukan untuk mendapatkan data mengenai respon dosen dan mahasiswa terhadap kinerja dosen. Secara keseluruhan, mahasiswa yang terlibat dalam penelitian ini sebanyak 118 orang, yang terdiri atas 68 orang mahasiswa (56.9\%) berasal dari FT dan Fakultas lain (FE dan FB Inggris). Dalam aspek persiapan perkuliahan, sebanyak 41 orang (62.1\%) mahasiswa menilai kinerja dosen Fakultas Teknik ke dalam kategori sedang, sebanyak 23 orang 
mahasiswa $(34.8 \%)$ menilai rendah, dan sebanyak 4 orang mahasiswa (3\%) menilai rendah sekali.

Untuk aspek proses atau pelaksanaan perkuliahan, sebanyak 31 orang mahasiswa (47.0\%) menilai kinerja dosen ke dalam kategori tinggi, sebanyak 18 orang mahasiswa $(24.3 \%)$ menilai sedang, sebanyak 10 orang mahasiswa $(13.2 \%)$ menilai kinerja dosen rendah sekali, dan sisanya sebanyak 7 orang mahasiswa $(15.6 \%)$ menilai kinerja rendah.

Berdasarkan hasil wawancara diperoleh mengenai (a) disiplin waktu selaras dengan jadwal perkuliahan atau beban kerja, (b) Karya Pendidikan dan Pengajaran, yang menghasilkan Modelmodel pembelajaran, (c) Karya Ilmiah, pada tingkat local (university), nasional, atau internasional, (d). Karya pengabdian pada masyarakat yang berupa penciptaan teknologi, peningkatan keterampilan, menghasilkan model yang dapat dikembangkan oleh masyarakat.

2. Desain model yang dapat diterapkan

Desain model yang dikembangkan untuk meningkatkan kualitas kinerja dosen adalah Quality Improvement Program (QIP). Sasaran penyelenggaraan QIP ini adalah peningkatan kualitas kinerja dosen dalam menjalankan tri dharma perguruan tinggi. Penyelenggaraan QIP sebagai suatu proses belajar terdiri dari dimensi pengetahuan/kompetensi, sikap profesional, kesiapan mental kerja, dan kemandirian.. Sasaran penyelenggaraan QIP ini adalah peningkatan kualitas kinerja dosen dalam menjalankan tri dharma perguruan tinggi. Penyelenggaraan QIP sebagai suatu proses belajar terdiri dari dimensi pengetahuan/kompetensi, sikap profesional, kesiapan mental kerja, dan kemandirian.

Model pengembangan QIP adalah sebagai berikut :

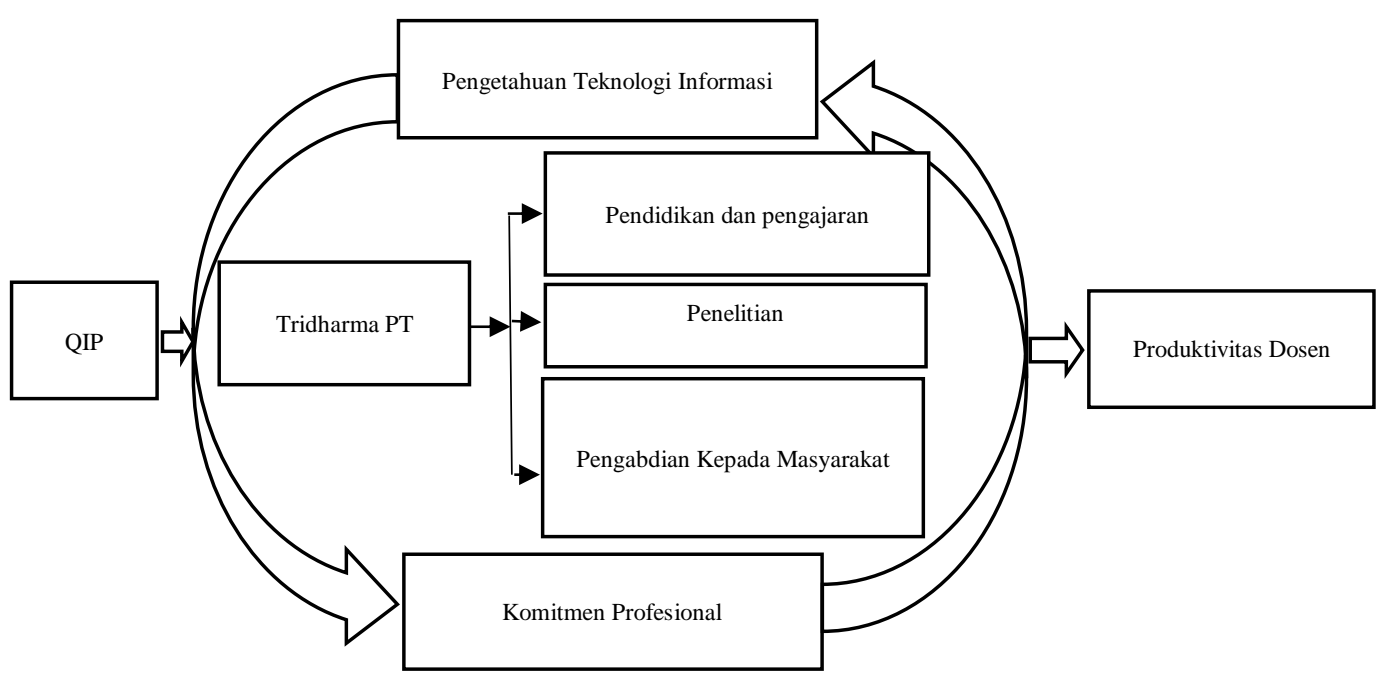

\section{KESIMPULAN}

Program pengembangan kualitas kinerja dosen dapat tercapai jika para dosen menjalankan tridharma perguruan tinggi yaitu menjalankan pendidikan dan pengajaran, penelitian, dan pengabdian kepada masyarakat dilaksanakan secara terintegrasi tidak terpisah ditunjang dengan pengetahuan teknolologi informasi dan komitmen professional dosen. Produktivitas dosen dalam hal ini tidak saja melaksanakan pendidikan dan pengajaran saja tetapi harus melaksanakan ketiga dharma tersebut. Dalam menjalankan tridharma pendidikan tidak akan tercapai secara optimal bila dosen tersebut tidak memiliki kemampuan teknologi informasi dan komitmen terhadap profesinya sebagai dosen. 


\section{DAFTAR PUSTAKA}

Satori, Djam'an., (2016). Pengawasan dan Penjaminan Mutu Pendidikan. Bandung: Alfabeta.

Kotter, John P., Heskett, James L., (1997). Manajemen Sumber Daya Manusia. Jakarta: PT Raja Grafindo Persada.

Ramli \& Jalinus, Nizwardi., (2013). Evaluasi Kinerja Guru Sekolah Menengah Kejuruan Sumatera Barat Pasca Sertifikai. Jurnal Penelitian dan Evaluasi Pendidikan, Vol. 17, No. 1.

Philbin, Ann \& Mikush, Sandra., (1999). A Framework for Organizational Development: The Why, What and How of OD Work. https://www.mrbf.org/sites/default/files/organizationaldevelopment.pdf. Diakses Tanggal 25 Mei 2018.

Peleyeju, J. O., \& Ojebiyi, O. A., (2013). Lecturer's Performance Appraisal and Total Quality Management of Public Universitites in South-Western Nigeria. British Journal of Education, Vol. 1, No. 2. http://www.eajournals.org. Diakses Tanggal 23 Mei 2018.

Bai, S., Rajput, Q., Hussain, S., \& Khoja, S.A., (2014). Faculty Performance Evaluation System: An Ontological Approach. Proceeding of IEEE/ACS International Conference on Computer Sysstem and Application, AICCSA, Vol. 2014). https://www.semanticscholar.org. Diakses Tanggal 23 Mei 2018

Langen, J. M., (2011). Evaluation od Adjunct Facultyin Higher Education Institutions. Assessment and Evaluation in Higher Education, Vol. 36, No. 2. https://www.tandfonline.com/doi/abs. Diakses Tanggal 23 Mei 2018

Borg, W.R. \& Gall, M.D. Gall. (2010). Applying Educational Research ;; sixth Edition. Pearson Education, New York: Longman. 